The books referred to below* deal with the applications of thermodynamics in chemistry; but that by Denbigh is of wider interest. They are all good and useful and can all be warmly recommended. Allard's book is very clear and interesting, starting at the beginning and deducing the equations from the fundamental laws. It has a fairly long section on the phase rule, which seems out of place, a good section on statistical mechanics, and a clear account of such parts of wave mechanics as are needed in this. The treatment is modern and the mathematics has been presented in an understandable form. It is a book very suitable for students.

The books by Rossini and Paul are based on the Lewis system; fugacity is rather fully dealt with by Rossini but only in passing by Paul. Both books attempt to start at the beginning. Rossini makes heavy weather of free energy by approaching it from entropy, and has more than a page in finding what is equivalent to equation 6 above, at the $\operatorname{sam} \theta \operatorname{tim} \theta$ making it clear that $\Delta G$ is only part of the free energy change, a point not always evident in American books. Rossini's definitions are careful and clear, but it is not obvious why he should bring in atomic energy in such detail, since thermodynamics does not deal with nuclear changes. In both books the symbol $F$ is used for $G$, and it is called free energy, which is confusing. Rossini, as might be expected, lays particular emphasis on experimental data, and his accounts of the calculation and use of thermodynamic quantities are admirable. He has not much to say of irreversible processes. Paul gives the usual treatment based on Clausius, which is not very clear ; he could with advantage have reconsidered this topic, since he obviously has the capacity for understanding difficult subjects and making them clear to students. Both Rossini and Paul deal with the DebyeHückel theory of strong electrolytes, but only Rossini deduces the equations. Both books deal with statistical mechanics, Paul's account being more readable and likely to be more intelligible to beginners. Both have problems, and Paul's gives answers. A section at the end of Rossini's book deals with the applications to such technical problems as fractionation, which should be useful to young chemists entering industry and called upon to put their knowledge into practice. In short, the books by Paul and Rossini are sound treatises written on American lines and bringing Lewis and Randall up to date.

Denbigh's book, I think, is not quite successful. It deals in a limited space with a rather difficult subject. It makes several re-starts on the same topic, which leaves the impression of a certain breathlessness, the $i$ and $k$ subscripts on pp. 27-29 are confusingly jumbled, and some of the statements, such as the one on p. 61 that both energy and entropy in thermodynamics are simply mathematical quantities, are rather startling. The real meaning of the heat of transport is not made very clear at the start, and the introduction of time into thermodynamics is not justified ; the procedure of converting an equation into a kinetic equation by dividing by $\mathrm{d} t(\mathrm{p} .46)$ requires

* Eléments de thermodynamique chimique. Par Georges Allard. (Bibliotheque d'Education par la Sclence.) Pp. 472. (Paris: Albin Michel, 1951.) 1380 francs.

Chemical Thermodynamics. By Prof. Frederic D, Rossini. Pp. $\mathrm{xix}+514$. (New York : John wiley and Sons, Inc.; London: Chapman and Hall, Ltd., 1950.) 488. net.

Principles of Chemical Thermodynamics. By Prof. Martin A. Paul (International Chemical Series.) Pp. viii +740 . (London: McGrawHill Publishing Co., Itd., 1951.) 648 .

The Thermodynamics of the Steady State. By Dr. K. G. Denbigh (Methuen's Monographs on Chemical Subjects.) Pp. vil +103. (London: Methuen and Co. more justification, and the statement that de Donder's treatment of thermodynamics is better than Lewis and Randall's (p. 45) would not be approved by Allard, who shows in his book (p. 198) that it has some undesirable features; and is also clear (p. 72) that the application of the principle of increase of entropy to a 'universe' is meaningless unless the universe is defined as a thermodynamic system, which is not done by those using the idea.

The subject of thermodynamics has developed very much in recent years, and much of this has come about by reason of its applications in chemistry. The chemist needs to know what is contained in such books as the above, and it would do the physicist and engineer no harm to know it either. The method of treatment suitable in the study of heat engines is less applicable in chemistry, and the special methods used in that science have amplified the scope of the subject and have also provided a bridge between classical thermodynamics and statistical mechanics which has led to many valuable interchanges of material from the two sciences. The study of irreversible changes still remains undeveloped and diffcult; but the material summarized in Denbigh's book shows that progress is being made in this field, and we may hope that before long many now fields of application will have been developed. Let those who think that thermodynamics is a closed subject reflect.

J. R. Partington

\section{MOISTURE RELATIONS AND FIBRE PROCESSING}

$\mathrm{D}$ URING the morning of September 9 at the recent meeting in Belfast of the British Association, Section A (Physics) held a session on the moisture relations of textile fibres, which consisted of two papers, one by Mr. J. A. Matthew, head of the Spinning Department of the Linen Industry Research Association, entitled "Moisture Absorption by Fibres and its Effect on Fibre Properties", and the other by Dr. A. B. D. Cassie, director of research at the Wool Industries Research Association, entitled "Moisture Relations and Clothing Comfort".

Mr. Matthew dealt with three main aspects of the problem. He discussed the relation between the amount of water absorbed by textile fibres and the atmospheric temperature and relative humidity, and also the effect of the absorbed water upon the physical properties of the fibre. He then gave some practical examples of the effect of humidity on the efficiency of the processing of flax fibres and yarn during spinning and weaving.

If fibre, yarn or cloth is stored in an atmosphere maintained at a constant temperature and relative humidity, the moisture content of the material, expressed as a percentage of the oven-dry weight, gradually attains a steady value called the "equilibrium regain'. The equilibrium regain of all textile fibres and their products depends primarily on the relative humidity and temperature of the air, but other factors, including the previous history of the material, also have their effect. If the material is wetted out and then allowed to reach its equilibrium regain at a constant temperature and at a series of progressively decreasing relative humidities, the regain values lie on a sigmoid desorption curve when plotted against the relative humidity. When the process is continued 
with ascending humidities, the regain values lie on a second sigmoid absorption curve which lies below the desorption isotherm curve, except at very low and very high humidities. A similar hysteresis effect occurs when absorption takes place as a result of increasing the humidity after partial desorption or when desorption occurs after partial absorption. Hysteresis also occurs when the material is brought to equilibrium in an atmosphere of constant humidity at temperatures which are progressively increased and afterwards decreased.

These effects are shown by the following materials : cotton, flax, hemp, jute, etc.; wood, silk and hairs; fibres manufactured by the regeneration of cellulose ; and some other materials such as wool and starch. For all these materials the absorption and desorption isotherms are very similar in shape, so that the ratio of the equilibrium regain of one material to that of another is very nearly the same at all humidities.

A few manufactured fibres such as cellulose acetate, nylon and 'Terylene' do not behave in this way. There is no point of inflexion in the curve at low humidities, the regain is quite small at all normal humidities, and there is very little difference between the absorption and desorption isotherms.

The equilibrium regain at given atmospheric conditions differs from one type of fibre to another. For example, at 65 per cent relative humidity and $65^{\circ} \mathrm{F}$. $\left(18 \cdot 3^{\circ}\right.$ C.) average values are as follows : wool 14 per cent, viscose rayon 13 per cent, green flax 11 per cent, silk 9.5 per cent, raw cotton 8 per cent; but with all natural fibres the equilibrium regains of different lots differ according to their origin and treatment.

The physical and mechanical properties of textile fibres depend upon the humidity of the air to which they have been exposed, and Mr. Matthew went on to deal with these effects in detail. The strength of fibres and of the yams and cloth manufactured from them depends upon the humidity of the atmosphere in which they have been conditioned. Vegetable fibres usually increase in strength with increase in relative humidity, whereas the reverse is the case with artificial and protein fibres; for example, linen yarns increase 25 per cent in strength when the humidity is increased from 50 to 90 per cent, whereas viscose rayon loses 40 per cent of its strength under similar conditions. The moduli of elasticity and rigidity of fibres decrease with increasing relative humidity. The frictional properties of textile fibres and yarns increase rapidly with increase in humidity ; but in most cases there is a reduction in the friction when a free film of water is present. The electrical properties of fibres and their products vary considerably with the regain. The conductivity of fibres is extremely low at low regains but increases very rapidly with increasing regain, while the dielectric constant remains fairly constant at low regains but thereafter increases rapidly with increase in regain. The variation in the electrical properties with regain forms the basis of electrical moisture meters; and, although the accuracy of these instruments is limited by differences between the behaviour of different batches of the material and a separate calibration is required for each type of fibre, the rapidity with which these instruments can be used more than offsets these disadvantages.

The absorption of water vapour by flax and other textile fibres and the consequent effects on their physical properties affect textile technology in many ways. After pointing out the need for control of the relative humidity in checking the weight per unit length of the yarn or the weight per unit area of the cloth, and the strength of the product, Mr. Matthew gave some examples taken from the spinning and weaving of linen, in which the atmospheric humidity has an important effect upon the efficiency of processing. In preparing flax fibre for spinning, the material passes through a number of frames on which it is drawn out by pairs of rollers rotating at different speeds. Fibre is liable to collect or 'lick-up' on these rollers, and when this happens the machine must be stopped for cleaning and so production is lost. 'Lick-up' can be considerably reduced by maintaining the flax at a suitable regain. In dry spinning, productivity is limited by breakages of the yarn, and the rate at which these breakages occur is much reduced by increasing the relative humidity. Similarly, in weaving, stoppages due to breakages of the warp yarn are reduced when the operation is carried out at a high temperature and humidity. Such atmospheric conditions, however, cause fatigue and discomfort to the workers, with a consequent reduction of output, so that in practice a compromise must be sought between the conditions which are most suitable for processing and those which are comfortable for the workers.

Dr. Cassie dealt with the thermal properties of clothing and showed how the interaction of the fibres with the water vapour in the atmosphere contributes in no small degree to the comfort of clothing by liberating heat when the wearer passes from a warm dry atmosphere to a cold damp one. Considering the thermal insulation, Dr. Cassie said that still air is the best insulator known to man, and fabrics make use of this property. The thermal conductivity of fabrics increases with their bulk density, and any increase in the amount of solid material of a fabric leads to a loss of heat insulation. Worsted fabrics contain about 60 per cent air, and the very large total surface area of the fibres-about $2,000 \mathrm{sq}$. $\mathrm{ft}$./1b. of wool-exerts a very effective drag on the air, which is thus maintained at rest within the fabric and provides excellent heat insulation.

The large surface of the fibres brings them into close contact with the surrounding atmosphere and enables them to interact with the water vapour. Recent research has shown that in such conditions the time required for water to diffuse from the surface to the centre of a fibre is always negligible compared with the time required for the diffusion of water vapour and the transfer of heat through the air entrapped by the fibres. Fibres can react rapidly with heat and water vapour provided that they are presented to the fibre as quickly as required. On the other hand, at normal atmospheric conditions such as $65^{\circ} \mathrm{F}$. and 60 per cent relative humidity, each c.c. of wool contains eighteen thousand times as much water as does the same volume of air, and this enormous difference between the water content of wool and air makes the approach to equilibrium slow when there is a relatively large bulk of wool.

The absorption of water vapour by fibres is accompanied by a large evolution of heat, and Dr. Cassie gave as an example the amount of heat liberated by a man's elothes when he goes out of doors from a well-ventilated and -heated room on a typical winter day in Britain. Assuming that the clothes contain five pounds of wool and that they are in equilibrium with the conditions indoors (namely, 65 $5^{\circ} \mathrm{F}$. and 
45 per cent relative humidity), they will absorb one pound of water when taken outside and allowed to re-condition at $40^{\circ} \mathrm{F} .\left(4 \cdot 4^{\circ}\right.$ C.) and 95 per cent relative humidity. In so doing they will liberate 1,200 B.Th.U. of heat. This amount of heat will provide excellent protection against the chill of a sudden temperature change provided that it is liberated at a suitable rate, and Dr. Cassie proceeded to show that the conditions within a fabric are such as to ensure that this heat is liberated at the optimum rate for protection against a sudden change of temperature.

The fibres are always in equilibrium with the air immediately surrounding them because absorption and desorption of water take place very rapidly; but the amount of water vapour absorbed from the air is so small compared with the water content of the fibres that their regain is virtually unchanged. The temperature of the air issuing from a mass of wool is therefore determined by the condition imposed by the fibres, namely, that the relative humidity must remain unchanged. The heat obtained. by condensing enough water vapour from any given volume of air to maintain a constant relative humidity when its temperature is decreased by 1 deg. C. is roughly equal to the heat required to raise the temperature of the air in the given volume by 1 deg. C. Thus, if the temperature of the air coming into contact with the textile is reduced by $10 \mathrm{deg}$. C. without change in the water vapour pressure, the air after passing through the textile will only be reduced by 5 deg. C., enough water having been condensed from the air by the textile to raise its temperature by $5 \mathrm{deg}$. C. This thermostatic effect of textiles is maintained over considerable periods because, fortunately, the diffusion constants for heat and for water vapour are almost the same, being $0.21 \mathrm{~cm} .{ }^{2} / \mathrm{sec}$. and $0.25 \mathrm{~cm} .{ }^{2} / \mathrm{sec}$, respectively. Thus the temperature and water vapour gradients are correctly maintained for securing the maximum effect in reducing the chill produced by a decrease in temperature.

The results of experiments designed to test the accuracy of these theoretical conclusions were then described by Dr. Cassie, who showed that excellent quantitative agreement has been obtained between the theoretical and actual results. The effect was studied of increasing the temperature of the air, passing through a mass of fibre, from $20^{\circ}$ to $35^{\circ} \mathrm{C}$. without change of vapour pressure, and it was found that the change in temperature of the emerging air was halted at $26^{\circ} \mathrm{C}$. The subsequent rate of increase in temperature was small, being least of all for wool and increasing in the order, wool, flax, silk and cotton. This corresponds to the order of the regains of the fibre, and, as predicted by the theory, the protection afforded by the fibres increases with the slope of the regain - relative humidity curves.

Finally, Dr. Cassie pointed out that a similar large thermostatic effect can result from textile furnishings. The increase in regain of a carpet when a room is left unheated results in the liberation of as much heat as would be given off by a $1-\mathrm{kW}$. electric fire burning for $1 \frac{1}{2}-2 \frac{1}{2} \mathrm{hr}$., the heat being liberated over a period of several days.

In the discussion which followed these two papers, Dr. R. W. Powell described experiments made at H.M. Norfolk Flax Establishment on the moisture relations of the growing flax plant, and pointed out that the normal date of pulling flax corresponds to the time at which the whole plant has a uniform moisture content. He mentioned experiments made on the heating up of stacks of flax straw and also described how the humidification of dry flax straw before scutching increases the yield of flax fibre.

Miss M. V. Griffiths asked whether the airing of domestic linen is really necessary, as a large amount of electricity is being consumed in modern houses for this purpose. Should the air movement be increased during drying in an airing cupboard or could a more efficient drying cupboard be designed? In reply, Mr. Matthew said that he regarded airing as a safety measure; linens stored in a folded condition in drawers would have little access to free air and so would not dry if they were put away damp. The rate of drying increases with increasing air velocity and temperature; usually the most economical method is to use some heat and a definite but not necessarily very large air velocity, on well exposed material. Dr. Cassie said that it is necessary for underwear to be dried to a low regain ; measurements have shown that, in the absence of perspiration, the air between the skin and underclothing has a relative humidity of only about 20 per cent, and underclothing should therefore be conditioned to this relative humidity by airing. J. L. SPENCER-SMITH

\section{AFFORESTATION OF MOORLAND}

$A \mathrm{~T}$ the meeting of the British Association in Belfast, Section $\mathrm{K}^{*}$ (Forestry) devoted a session during the morning of September 8 to the consideration of sylvicultural problems resulting from recent large-scale planting on moorland soils. The need for a considerable extension of the forest area in Britain - a need admitted by men of all shades of opinion-.has led to the formation of large plantations on heathland and moorland mainly in the upland regions. The current annual planting programme, in State forests alone, of approximately sixty thousand acres requires the use of large areas of these types of land, and work has been going on actively since 1919 in such diverse conditions as those afforded, for example, by the Yorkshire moors, the peat-covered Border country, the upland heaths of north-east Scotland, of Wales and of south-west England, and the blanket bog of the north-west of England. In forming their plantations, foresters had little to guide them at first except the existence of one or two relatively small plantations, the history of which had been recorded. They have had to hammer out their own technique. The need for carefully conducted experimental work was early recognized, and the large number of experiments carried out in the west and in the north, covering a wide range of subjects, such as choice of species, methods of planting, ploughing, drainage and the use of fertilizers, has had a marked influence on the course of events.

J. M. B. Brown (Forest Research Station, Alice Holt), in a paper on "The Role of Indicator Plants in Moorland Afforestation", discussed the use of the natural flora of moorlands and heathlands as a guide in the selection of tree species for planting. The vegetation on the ground before planting has been extensively used during the past thirty years for determining what land is plantable and what is unplantable and for allocating tree species to the various sites. Interpreted with discretion, the natural flora may give useful information by indicating which species of tree appears to be suitable to the local 